\title{
Increasing the catalytic performance of erionite by \\ hierarchization
}

Justyna Tekla ${ }^{a}$, Louwanda Lakiss ${ }^{b}, V$ Valentin Valchev ${ }^{b}$, Karolina A. Tarach ${ }^{a}$, Magdalena Jabłońska ${ }^{c}$, Vladimir Girman ${ }^{d}$, Agnieszka Szymocha $^{f}$, Andrzej Kowalczyk ${ }^{a}$, Kinga Góra-Marek ${ }^{\mathrm{a} *}$, Jean-Pierre Gilson $^{b *}$

${ }^{\text {a }}$ Faculty of Chemistry, Jagiellonian University in Kraków, Gronostajowa 2, 30-387 Kraków, Poland

${ }^{b}$ Normandie Université, ENSICAEN, UNICAEN, CNRS, Laboratoire Catalyse et Spectrochimie (LCS), 14000 Caen, France

${ }^{c}$ Center for Automotive Catalytic Systems Aachen, RWTH Aachen University, Schinkelstr. 8, 52062 Aachen, Germany

${ }^{d}$ Pavol Jozef Šafárik University in Košice, Department of Condensed Matter Physics, Park Angelinum 9, 04154 Košice, Slovakia

${ }^{f}$ Faculty of Agriculture and Economics, University of Agriculture in Krakow, Al. Mickiewicza 21, 31-120 Krakow

corresponding authors: Kinga Góra-Marek, +481268624 60, kinga.goramarek@gmail.com Jean-Pierre Gilson, +33 2314528 15, gilson@ensicaen.fr 


\begin{abstract}
The texture and acidity of a parent synthetic erionite zeolite (ERI structure) are modified by a twostep top-down treatment involving acid $\left(\mathrm{HNO}_{3}\right)$ and base $(\mathrm{NaOH})$ biased leaching as well as an unbiased $\mathrm{HF} / \mathrm{NH}_{4} \mathrm{~F}$ leaching. These zeolites are compared to a bottom-up prepared nanosized ERI, UZM-12. The structural (XRD, ${ }^{29} \mathrm{Si}$ MAS NMR), textural ( $\mathrm{N}_{2}$ adsorption-desorption, STEM) and acidic (FT-IR spectroscopy of adsorbed probe molecules) properties of the parent and hierarchical ERI are also carefully monitored. Among all top-down hierarchization strategies applied for 8-ring ERI structure, the sequential leaching in acid $\left(\mathrm{HNO}_{3}\right)$ and caustic $(\mathrm{NaOH})$ solutions is the most efficient to add mesoporosity to the native microporosity. The catalytic performances of the hierarchical materials and their parent are assessed in the dealkylation of 1,3,5-triisopropylbenzene (TiPBz); they are in line with the mesoporous external surface area and the external surface acid site density for all samples. The best top-down hierarchical ERI has similar catalytic properties as the nanosized ERI, UZM-12.
\end{abstract}

Keywords: erionite, demetallation, hierarchical zeolites, 1,3,5-triisopropylbenzene dealkylation 
Erionite (ERI-type framework) is a naturally occurring zeolite of wool-like appearance $[1,2]$ discovered and described by A. S. Eakle in 1898 [1]. It is a low silica zeolite (Si/Al 3) [3,4]. Its structure, first determined by L. W. Staples and J. A. Gard [3], consists of a three-dimensional network of elliptical 8ring channels $(0.36 \times 0.51 \mathrm{~nm})$ running along the [001] direction and restricting the access to a large cage (1.51 nm length) [2]. It belongs therefore to the family of small pore zeolites.

It is the first and only natural zeolite used commercially in a refinery process, Selectoforming ${ }^{\circledR}$, designed to selectively crack low octane linear paraffins downstream a naphtha reformer. It has since been displaced by a more selective, isomerization process, M-Forming ${ }^{\circledR}$, based on a MFI catalyst [58]. A fibrous aluminosilicate, natural erionite causes serious health issues and exposure is associated, like asbestos, with increased risks of lung cancer and mesothelioma [9]. A low silica (Si/Al=3.5) synthetic erionite is commercially available from Clariant (CZE 7). An ERI-type zeolite discovered by UOP, UZM-12 synthesized in the presence of organic structure directing agents, possesses attractive features (Si/Al > 5.5, spherical morphology, nanosized crystals [100 nm] and good hydrothermal stability) $[10,11]$. These synthetic forms of ERI do not suffer from the severe health drawbacks of their natural counterparts and have potential applications in hydrocarbon processing.

However, the small pores of erionite bring diffusional constrains and restrict reactants accessibility to the active sites located in the micropores. Diffusion limitations can be reduced by generating intraand/or inter-particle mesopores by bottom-up (e.g. synthesis of nanosized crystals with intercrystalline mesoporosity) [12-18] and top-down (e.g. selective or non-selective leaching of tetrahedral elements resulting in additional intracrystalline mesoporosity) $[19,20]$ approaches. The reduced path length for reactants and products further decreases the extent of many secondary reactions, including the formation of coke precursors. Several approaches are available to introduce mesoporosity in intermediate (10-ring) and large (12-ring) pore zeolites such as MFI [19,21,22], BEA $[23,24]$ MOR [25], albeit with some restrictions. Strategies to hierarchize small pore (8-ring) zeolites are less developed and most attempts were not very successful due to the limited diffusion of extracted silica moieties through 8-ring micropores. [26]. The formation of intra-crystalline mesoporosity by demetallation of zeolites depends not only on their structure but also on the concentration and location of framework aluminum. Al-rich zeolites are however less responsive to a caustic treatment due to the protecting role of negatively charged $\mathrm{AlO}_{4}{ }_{4}^{-}$. Therefore, an initial dealumination of the zeolite leading to higher $\mathrm{Si} / \mathrm{Al}$ ratio facilitates their subsequent desilication $[21,27]$. On the other hand, an approach based on bi-fluoride anions [28] offers the advantage of 
unbiased extraction of silicon and aluminum from zeolite frameworks while the routes based on acid or base leaching are biased towards Al or Si respectively.

In the present study, starting with a commercial ERI zeolite (CZE 7, Clariant) we screen a combination of dealumination (nitric acid), desilication (alkaline solutions) and $\mathrm{HF} \& \mathrm{NH}_{4} \mathrm{~F}$ leaching procedures to modify the texture and acidity of the parent erionite. Previous studies already demonstrated that a sequence of dealumination-desilication significantly modifies the structural, textural and acidic properties of mordenite and zeolite L (both low Si/Al but large pores) $[25,29]$. The Fluoride etching approach proceeds by eliminating the interfaces between intergrown crystals preserving only the highly crystalline domains. Therefore extra framework species are scarce and the secondary mesoporosity is not increased substantially [28]. Some key physico-chemical properties of the zeolites after hierarchization are monitored, namely: composition (ICP OES), structure (XRD and ${ }^{29} \mathrm{Si}$ NMR,), texture (low-temperature $\mathrm{N}_{2}$ physisorption, STEM) and acidity (FT-IR spectroscopy with various probe molecules). The parent ERI and its derivatives are also characterized by their catalytic performances in 1,3,5-triisopropylbenzene (TiPBz, kinetic diameter $0.95 \mathrm{~nm}$ ) dealkylation to assess the activity of the mesoporous surface created during hierarchization.

\section{EXPERIMENTAL}

\subsection{Catalyst preparation}

The parent ERI (Si/Al = 3.5) is purchased from Clariant, transformed by calcinaton to its $\mathrm{H}$-form prior to any hierarchization by demetallation. All these post-synthesis treatments are summarized in Table 1.

Table 1. Sample notation and treatment conditions.

\begin{tabular}{|c|c|c|}
\hline Sample name & Sample symbol & Conditions of modification \\
\hline Parent ( $\mathrm{NH}_{4}$-form) & ERI & \\
\hline Protonic form of erionite & H-E & Calcination $^{a}$ \\
\hline Desilicated with $\mathrm{NaOH}$ & E_b & $\begin{array}{l}\text { desilication with } 0.2 \mathrm{M} \mathrm{NaOH} \text { at } 338 \mathrm{~K} \text { for } 0.5 \mathrm{~h}(100 \mathrm{ml} \text { of } \mathrm{NaOH} \\
\text { per } 3.0 \mathrm{~g} \text { of zeolite); ion exchange treatment }{ }^{\mathrm{b}} \text {; calcination }{ }^{\mathrm{a}}\end{array}$ \\
\hline $\begin{array}{l}\text { Desilicated with } \mathrm{NaOH} \\
\text { and } \mathrm{HNO}_{3} \text { leached }\end{array}$ & E_b-a & $\begin{array}{l}\text { desilication with } 0.2 \mathrm{M} \mathrm{NaOH} \text { at } 338 \mathrm{~K} \text { for } 0.5 \mathrm{~h} \text { and subsequent } \\
\text { dealumination with } 0.15 \mathrm{M} \mathrm{HNO}_{3} \text { at } \mathrm{RT} \text { for } 3 \mathrm{~h}(100 \mathrm{ml} \text { of } \mathrm{NaOH} \\
\text { or } \mathrm{HNO}_{3} \text { per } 3.0 \mathrm{~g} \text { of zeolite); ion exchange treatment } \\
\text { calcination }{ }^{\text {a }}\end{array}$ \\
\hline $\begin{array}{l}\text { Desilicated with } \mathrm{NaOH} \text { in the } \\
\text { presence of microwave } \\
\text { radiation }\end{array}$ & E_mb & $\begin{array}{l}\text { desilication with } 0.2 \mathrm{M} \mathrm{NaOH} \text { at } 338 \mathrm{~K} \text { for } 0.5 \mathrm{~h} \text { under microwave } \\
\text { radiation } \mathrm{h}(100 \mathrm{ml} \text { of } \mathrm{NaOH} \text { per } 3.0 \mathrm{~g} \text { of zeolite); ion exchange } \\
\text { treatment }^{\mathrm{b}} \text {; calcination }{ }^{\mathrm{a}}\end{array}$ \\
\hline
\end{tabular}




\begin{tabular}{|c|c|c|}
\hline $\begin{array}{l}\text { Desilicated with } \mathrm{NaOH} \text { in the } \\
\text { presence of microwave } \\
\text { radiation and } \mathrm{HNO}_{3} \text { leached }\end{array}$ & E_mb-a & $\begin{array}{l}\text { desilication with } 0.2 \mathrm{M} \mathrm{NaOH} \text { at } 338 \mathrm{~K} \text { for } 0.5 \mathrm{~h} \text { under microwave } \\
\text { radiation and subsequent dealumination with } 0.15 \mathrm{M} \mathrm{HNO}_{3} \text { at } \mathrm{RT} \\
\text { for } 3 \mathrm{~h} \mathrm{~h}\left(100 \mathrm{ml} \text { of } \mathrm{NaOH} \text { or } \mathrm{HNO}_{3} \text { per } 3.0 \mathrm{~g} \text { of zeolite); ion }\right. \\
\text { exchange treatment }^{\text {b }} \text {; calcination }\end{array}$ \\
\hline Dealuminated with $\mathrm{HNO}_{3}$ & E_a & $\begin{array}{l}\text { dealumination with } 0.3 \mathrm{M} \mathrm{HNO}_{3} \text { at } 338 \mathrm{~K} \text { for } 0.5 \mathrm{~h}(100 \mathrm{ml} \text { of } \\
\mathrm{HNO}_{3} \text { per } 3.0 \mathrm{~g} \text { of zeolite); ion exchange treatment }{ }^{\mathrm{b}} \text {; calcination }\end{array}$ \\
\hline $\begin{array}{l}\text { Dealuminated with } \mathrm{HNO}_{3} \\
\text { and desilicated with } \mathrm{NaOH}\end{array}$ & $E_{-} a-b$ & $\begin{array}{l}\text { dealumination with } 0.3 \mathrm{M} \mathrm{HNO} \text { at } 338 \mathrm{~K} \text { for } 0.5 \mathrm{~h} \text { and } \\
\text { subsequent desilication with } 0.2 \mathrm{M} \mathrm{NaOH} \text { at } 338 \mathrm{~K} \text { for } 0.5 \mathrm{~h} \mathrm{~h} \\
\left(100 \mathrm{ml} \text { of } \mathrm{HNO}_{3} \text { or } \mathrm{NaOH} \text { per } 3.0 \mathrm{~g} \text { of zeolite); ion exchange }\right. \\
\text { treatment }{ }^{\mathrm{b}} \text {; calcination }{ }^{\text {a }}\end{array}$ \\
\hline Modified with $\mathrm{HF}$ and $\mathrm{NH}_{4} \mathrm{~F}$ & E_hf & $\begin{array}{l}\text { modification with } 0.5 \mathrm{M} \mathrm{HF} \text { and } \mathrm{NH}_{4} \mathrm{~F}\left(2.5 \mathrm{~g} \mathrm{NH}_{4} \mathrm{~F} \text { per } 0.5 \mathrm{~g} \text { of }\right. \\
\text { zeolite) at } \mathrm{RT} \text { for } 15 \mathrm{~min}\left(15 \mathrm{ml} \text { of } \mathrm{HF} \& \mathrm{NH}_{4} \text { solution per } 0.5 \mathrm{~g} \text { of }\right. \\
\text { zeolite); calcination }{ }^{\text {a }}\end{array}$ \\
\hline \multicolumn{3}{|c|}{$\begin{array}{l}\text { ( } a \text { - dealumination with } \mathrm{HNO}_{3} ; b \text { - desilication with } \mathrm{NaOH} ; m b \text { - desilication with } \mathrm{NaOH} \text { in the presence of microwave } \\
\text { radiation; } h f \text { - modification with } \mathrm{HF} \text { and } \mathrm{NH}_{4} \mathrm{~F} \text { ) }\end{array}$} \\
\hline \multicolumn{3}{|c|}{$\begin{array}{l}\text { a The resulting samples were calcined at } 723 \mathrm{k} \text { for } 8 \mathrm{~h} \text { with the temperature rate } 1.5 \mathrm{~K} / \mathrm{min} \text {. } \\
{ }^{\mathrm{b}} \text { After modifications the zeolites were three-fold ion-exchanged in the } 0.5 \mathrm{M} \mathrm{NH}_{4} \mathrm{NO}_{3} \text { solution at } 333 \mathrm{~K} \text { for } 1 \mathrm{~h} \text {. Then the } \\
\text { samples were filtrated, washed with distillated water and dried at room temperature }\end{array}$} \\
\hline
\end{tabular}

1 The UZM-12 zeolite was synthesized using the Charge Density Mismatch (CDM) approach given in ref 2 [30]. The final gel contained tetraethylammonium hydroxide TEAOH (35\% aqueous solution), 3 aluminum trisec-butoxide (Al(secOBut) ${ }_{3}$ ), colloidal silica (Ludox AS-40) and potassium chloride. The

4 final composition of the synthesis mixture was $13.0 \mathrm{TEAOH}: 16 \mathrm{SiO}_{2}: 1.0 \mathrm{Al}(\mathrm{secOBut})_{3}: 400 \mathrm{H}_{2} \mathrm{O}: 0.5$

$5 \mathrm{KCl}: 1.0\left(\mathrm{Me}_{6}\right.$-diquat-4) $\mathrm{Br}_{2}$ where $\mathrm{Me}_{6}$-diquat-4 is diquaternary $N, N, N, N^{\prime}, N^{\prime}, N^{\prime}$-hexamethylbutane-

6 diammonium ion $\left(\mathrm{CH}_{3}\right)_{3} \mathrm{~N}^{+}\left(\mathrm{CH}_{2}\right)_{4} \mathrm{~N}^{+}\left(\mathrm{CH}_{3}\right)_{3}$. The mixture was stirred vigorously at room temperature for

$7 \quad 12 \mathrm{~h}$, then transferred to teflon lined 45-ml autoclaves for the synthesis

8 (373 K, 7 days). Then, the solid products were harvested by filtration, washed repeatedly with water,

9 dried overnight at $373 \mathrm{~K}$, followed by calcination in air at $823 \mathrm{~K}$ for $10 \mathrm{~h}$, to remove the occluded

10 template. In order to obtain the protonic form (H-UZM-12), the calcined material was ion-exchanged

11 with a $1.0 \mathrm{M} \mathrm{NH}_{4} \mathrm{NO}_{3}$ solution, at $353 \mathrm{~K}$ for $6 \mathrm{~h}$, washed thoroughly with deionized water and then 12 calcined at 723 for $8 \mathrm{~h}$.

\subsection{Characterization methods}

The Si and Al content of the parent and hierarchical zeolites were determined by ICP OES with an Optima 2100DV (PerkinElmer) spectrometer.

The X-ray diffraction (XRD) patterns were recorded on a D2 Phaser diffractometer (Bruker) using $\mathrm{Cu}$ K $\alpha$ radiation $(\lambda=1.54060 \AA, 30 \mathrm{kV}, 10 \mathrm{~mA})$.

The specific surface areas and pore volumes were determined by $\mathrm{N}_{2}$ sorption at $77 \mathrm{~K}$ using a 3 Flex (Micromeritics) automated gas adsorption system. Prior to analysis, all samples were degassed under 
vacuum at $523 \mathrm{~K}$ for $24 \mathrm{~h}$. Their specific surface area $\left(\mathrm{S}_{\mathrm{BET}}\right)$ was determined using the BET (BrunauerEmmett-Teller) model according to Rouquerol's recommendations [31]. The micropore volume $\left(\mathrm{V}_{\text {micro }}\right)$ and specific surface area of micropores $\left(\mathrm{S}_{\text {micro }}\right)$ were calculated using the Harkins-Jura model (t-plot analysis). All textural parameters are summarized in Table 1 and Table 1_Sl.

The micrographs were obtained with a transmission electron microscope (JEOL 2100F) working at 200 KV with a Field Emission Gun (FEG), EDX analysis capabilities and STEM detectors for the bright and dark mode.

The solid-state MAS NMR spectra were acquired on an APOLLO console (Tecmag) at a magnetic field of $7.05 \mathrm{~T}$ (Magnex). For the ${ }^{29} \mathrm{Si}$ MAS-NMR spectra, a $3 \mu \mathrm{s} r$ pulse ( $\pi / 2$ flipping angle) was used and the samples spun at the magic angle spinning with a4 $\mathrm{kHz}$ spinning speed; 256 spectra were accumulated with a delay of $40 \mathrm{~s}$. The ${ }^{27} \mathrm{Al}$ MAS-NMR spectra were recorded using a $2 \mu$ srf pulse $(\pi / 6$ flipping angle), $8 \mathrm{kHz}$ magic angle spinning speed, and 1000 scans with an acquisition delay of $1 \mathrm{~s}$. The frequency scales in ppm were referenced to TMS and to $1 \mathrm{M}$ solution of $\mathrm{Al}\left(\mathrm{NO}_{3}\right)_{3}$, for the ${ }^{29} \mathrm{Si}$ and ${ }^{27} \mathrm{Al}$ spectra, respectively. All spectra were normalized to the mass of sample.

All IR spectra were recorded with a Bruker Vertex 70 spectrometer equipped with an MCT detector. The spectral resolution was of $2 \mathrm{~cm}^{-1}$. All the IR spectra were normalized to the same mass of sample (10 mg).

Prior to FT-IR studies, all samples were pressed into self-supporting wafers $\left(\mathrm{ca} .5 \mathrm{mg}^{-1} \cdot \mathrm{cm}^{2}\right.$ ) and thermally treated in-situ in a quartz home-made IR cell at $723 \mathrm{~K}$ under high vacuum for $1 \mathrm{~h}$. Quantitative acid sites titration were carried out with ammonia (PRAXAIR) and pyridine (POCh, Gliwice, Poland) as probe molecules. An excess of pyridine and ammonia was adsorbed at 443 and $403 \mathrm{~K}$ respectively, then physisorbed molecules were subsequently removed by the evacuation at the same temperature. The evacuation of ammonia at $403 \mathrm{~K}$ was effective to remove gaseous and physisorbed probe molecules (disappearance of ammonia dimers bands: 1465 and $1505 \mathrm{~cm}^{-1}$ ) [32].

The concentration of Brønsted and Lewis acid sites was calculated from the intensities of the 1545 and $1435 \mathrm{~cm}^{-1}$ bands (for $\mathrm{PyH}^{+}$and $\mathrm{NH}_{4}{ }^{+}$, respectively) and of 1450 and $1620 \mathrm{~cm}^{-1}$ bands (for PyL and $\mathrm{NH}_{3} \mathrm{~L}$, respectively), by using reliable extinction coefficients of these bands $[33,34]$. The extinction coefficients for the ammonia bands adsorbed on erionite were determined by stepwise addition of ammonia doses on $\mathrm{H}$-ERI; their values $\left(\mathrm{NH}_{4}{ }^{+}\right.$band: $\left.13.5 \mathrm{~cm} \cdot \mu \mathrm{mol}{ }^{-1}\right)$ extracted from the slopes of linear plots of the band intensities (band area) variations with the amount of adsorbed ammonia. 
The acid strength was evaluated by $\mathrm{NH}_{3}$ thermo-desorption where the $\mathrm{NH}_{4}{ }^{+}$and $\mathrm{NH}_{3} \mathrm{~L}$ bands retained at $623 \mathrm{~K}$ was considered to indicate acid strength.

Pivalonitrile ( $\mathrm{Pn}, 98 \%$, Sigma-Aldrich) was adsorbed on the zeolites at room temperature followed by 20 min evacuation at the same temperature to remove any physisorbed $\mathrm{Pn}$. The concentration of the Brønsted and Lewis acid sites detected by the Pn was calculated from the maximum intensities (band height) of the respective bands at $2277 \mathrm{~cm}^{-1}$ and $2305 \mathrm{~cm}^{-1}$ and their extinction coefficient (0.11 and $0.15 \mathrm{~cm}^{2} \cdot \mu \mathrm{mol}^{-1}$, resp.). The number of sites exposed on the mesopore surface were determined according to the procedure given in ref [35]. The accessibility index $\left(A F_{P n}\right.$ or $\left.A F_{P y}\right)$ of these probe molecules were calculated by comparing the Brønsted acid site densities they measured with the total Brønsted acidity expected from the Al chemical analysis.

\subsection{Dealkylation of 1,3,5-tri-isopropylbenzene (TiPBz)}

The catalytic dealkylation of 1,3,5-triisopropylbenzene (TiPBz) was performed in a tubular down flow reactor. The $\mathrm{H}$-form of zeolite $(50 \mathrm{mg}$ or $20 \mathrm{mg}$ ) was loaded in the reactor, dehydrated under a dryair flow $\left(60 \mathrm{~mL} \cdot \mathrm{min}^{-1}\right)$ at $393 \mathrm{~K}$ for $1 \mathrm{~h}$, the temperature raised to $673 \mathrm{~K}$ (rate $2 \mathrm{~K} \cdot \mathrm{min}^{-1}$ ) followed by a $4 \mathrm{~h}$ plateau at the final temperature. A dry nitrogen flow $\left(200 \mathrm{~mL} \cdot \mathrm{min}^{-1}\right)$ was introduced at $676 \mathrm{~K}$ and the reactor cooled to reaction temperature $(498 \mathrm{~K})$; the nitrogen stream was subsequently diverted to a saturator filled with 1,3,5-triisopropylbenzene $\left(\mathrm{P}_{\mathrm{TPBz}}=184 \mathrm{~Pa}\right)$. The total pressure was $P_{\text {Tot }}=1.01$ $\times 10^{5}$ and the resulting space time $\mathrm{W} / \mathrm{F}^{\circ}=44.2 \mathrm{~g} \cdot \mathrm{h} \cdot \mathrm{mol}^{-1}$ and $20 \mathrm{~g} \cdot \mathrm{h} \cdot \mathrm{mol}^{-1}$ when $50 \mathrm{mg}$ or $20 \mathrm{mg}$ of the catalyst was applied, respectively. The initial conversions were measured at $498 \mathrm{~K}$ after a time on stream of $5 \mathrm{~min}$.

\section{RESULTS AND DISCUSSION}

\subsection{Physicochemical properties of the catalysts}

The $\mathrm{Si} / \mathrm{Al}$ of alkaline leached erionite $\left(\mathrm{E}_{-} b\right)$ and erionite modified under microwave heating $\left(\mathrm{E}_{-} m b\right)$ are almost constant and unchanged compared to their parent, highlighting the resilience of low Si/Al zeolites to caustic treatments (Table 1_SI, Table 1). The presence of many $\mathrm{AlO}_{4}{ }^{-}$tetrahedra inhibits the demetallation process due to the electrostatic repulsion of the $\mathrm{OH}^{-}$ions. Silicon extraction from the zeolite framework is further inhibited by the presence of 8-membered rings channels ensuring a high stability of $\mathrm{Si}$ atoms and constraining the diffusion of extracted silicate species in the micropores. 
A more effective method of Si removal from Al-rich frameworks is a sequential dealumination and desilication ( $\left.\mathrm{E} \_a-b\right)$; the increased amount of silicon extracted is related to the lower number of $\mathrm{Al}$ atoms and the presence of additional defects in the zeolite, potential $\mathrm{OH}^{-}$group attack points. The fluoride treatment on the other hand is unbiased and the Si/Al ratio changes marginally upon treatment (E_hf).

The XRD patterns are typical of pure ERI ( $\mathrm{PG}_{3} / \mathrm{mmc}$ space group) (Fig. 1, Fig. 1_SI) as reported elsewhere $[4,36]$. Some amorphous material is present on the acid-leached E_a, most probably related to extra-framework aluminous species generated during the acid extraction.

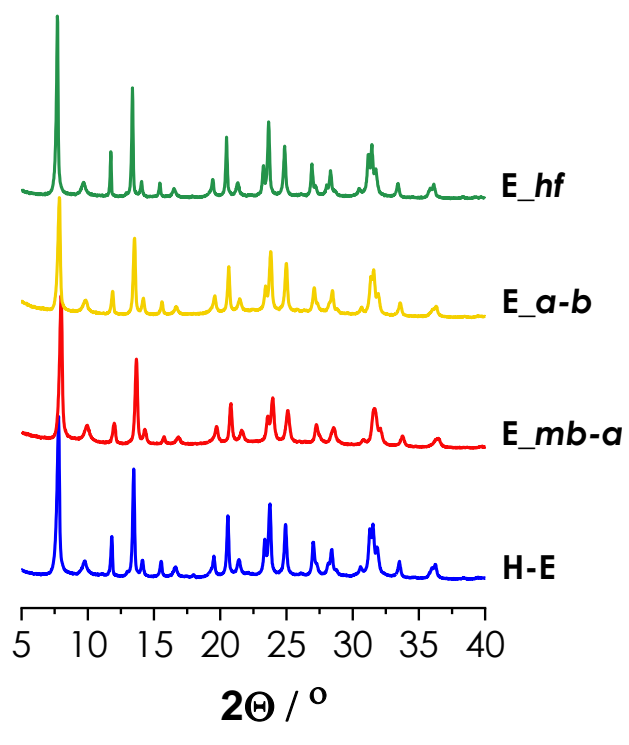

Fig. 1. XRD patterns of the parent and hierarchical erionites.

The main goal of the zeolite demetallation is to add mesoporosity to the native microporosity. The transport of reactants and products, is enhanced by the presence of intracrystalline mesoporosity, and limits less the kinetics of most reactions. However, the microporosity needs to be preserved in order to enjoy the benefits of shape selectivity. The evolution of the porosity of all erionites is monitored by low-temperature $\mathrm{N}_{2}$ physisorption. The samples with the most developed mesoporosity are highlighted in Table 1 and the others in Table 1_SI. H-E has the expected micropore volume of an ERI structure $\left(0.22 \mathrm{~cm}^{3} \cdot \mathrm{g}^{-1}\right)$; the small hysteresis loop in the $\mathrm{N}_{2}$ adsorption-desorption isotherm (Fig. 2a , Fig. 2_SI) is due either to surface roughness of zeolitic grains and/or agglomerated crystals. Both textural parameters and STEM micrographs (Fig. $2 a$ ) indicate that a sequential dealumination-desilication procedure $\left(\mathrm{E}_{-} a-b\right)$ increases intracrystalline mesoporosity. This is further highlighted by the presence of more external silanols, the $3747 \mathrm{~cm}^{-1}$ band on the IR spectra (Fig. $3 a$, Fig. 3_SI). The linear dependency between the area of these silanols and the mesopore surface area (Fig. $3 b$ ) indicates a clear link between these two features. On the fluorine treated erionite $E_{-} h f$, the 
1 increase of both $S_{\text {meso }}$ and $V_{\text {meso }}$ is moderate while the microporosity is preserved $\left(V_{\text {micro }}=0.22 \mathrm{~cm}^{3} \cdot \mathrm{g}^{-1}\right)$

2 (Table 1); this confirms that such a treatment dissolves the interface between crystalline domains

3 and then the crystal faces are attacked, as indicated on STEM micrographs (Fig. 2a).

4 The ${ }^{29}$ Si MAS NMR spectra of the parent, $\mathrm{H}-\mathrm{E}$, and its hierarchical derivativess are presented in Fig.

$52 \mathrm{~b}$. The generation of mesoporosity by caustic treatment results in a decrease of the $\mathrm{Si}(3 \mathrm{Si}, 1 \mathrm{Al})$

6 intensity alongside an increase of the Si(4Si,OAI) signal. This local Si/Al increase, also evidenced by

7 chemical analysis ( $\mathrm{Si} / \mathrm{Al}_{\mathrm{ICP}}$, Table 1 ) is characteristic of the acid/alkaline post-synthesis treatments.

8 Only aluminum in tetrahedral coordination is observed for the parent and its $\mathrm{E}_{-} a-b$ and $\mathrm{E}_{-} h f$ by ${ }^{27} \mathrm{Al}$

9 MAS NMR spectroscopy (Fig. $3 b$ ). In the E_mb-a, a small amount of octahedral aluminum ( $0 \mathrm{ppm}$ ) is

10 detected but suggests that the added mesoporosity facilitates the formation extra-framework

11 aluminum. The lower number of Al-rich units, i.e., Si(3Si, 1Al), Si(2Si,2Al), Si(1Si,3Al) in the UZSM-12

12 and the presence of extra-framework aluminum implies a lower framework Al concentration in this

13 bottom-up prepared hierarchical ERI. No substantial changes in the NMR characteristics are detected

14 after fluoride treatment. 
Table 1. Composition (Si/Al, Al), texture (surface area and volume of micro- and mesopores ), acidity (concentration and strength of Brønsted (B.a.s.) and Lewis (L.a.s.) acid sites from quantitative IR ammonia and pyridine sorption studies) and accessibility from quantitative IR pyridine $\left(A F_{P_{y}}\right)$ and pivalonitrile $\left(A F_{P_{n}}\right)$ sorption studies.

\begin{tabular}{|c|c|c|c|c|c|c|c|c|c|c|c|c|c|c|c|c|}
\hline \multirow{3}{*}{ sample } & \multirow{3}{*}{$\begin{array}{l}\mathrm{Si} / \mathrm{Al} \\
\mathrm{ICP}\end{array}$} & \multirow{3}{*}{$\begin{array}{l}\text { Si/Al } \\
\text { NMR }\end{array}$} & \multirow{3}{*}{$\begin{array}{c}\text { Al } \\
\mu \mathrm{mol} \cdot \mathrm{g}^{-1}\end{array}$} & \multirow[t]{3}{*}{$S_{\text {BET }}$} & \multirow{3}{*}{$\frac{S_{\text {micro }}}{m^{2} \cdot g^{-1}}$} & \multirow[t]{3}{*}{$S_{\text {meso }}$} & \multirow{3}{*}{$\begin{array}{r}\mathbf{V}_{\text {micro }} \\
\mathrm{cm}^{3}\end{array}$} & \multirow{3}{*}{$\frac{V_{\text {meso }}}{g^{-1}}$} & \multicolumn{3}{|c|}{$\begin{array}{c}\text { B. a. s } \\
\text { concentration }\end{array}$} & \multirow{2}{*}{$\begin{array}{l}\text { B. a. s strength } \\
\mathrm{NH}_{3(350)} / \mathrm{NH}_{3(170)}\end{array}$} & \multicolumn{2}{|c|}{$\begin{array}{c}\text { L. a. s } \\
\text { concentration }\end{array}$} & \multirow{3}{*}{$\begin{array}{c}\mathrm{AF}_{\mathrm{Py}} \\
\%\end{array}$} & \multirow{3}{*}{$\begin{array}{r}\mathrm{AF}_{\mathrm{Pn}} \\
\%\end{array}$} \\
\hline & & & & & & & & & $\mathrm{NH}_{3}$ & Py & $\mathrm{Pn}$ & & $\mathrm{NH}_{3}$ & Py & & \\
\hline & & & & & & & & & \multicolumn{3}{|c|}{$\mu \mathrm{mol} \cdot \mathrm{g}^{-1}$} & - & \multicolumn{2}{|c|}{$\mu \mathrm{mol} \cdot \mathrm{g}^{-1}$} & & \\
\hline H-E & 3.5 & 4.2 & 2350 & 521 & 575 & 19 & 0.22 & 0.08 & 1371 & 64 & 10 & 0.88 & 211 & 173 & 3 & 0 \\
\hline E_mb-a & 4.5 & 5.7 & 1920 & 530 & 472 & 58 & 0.20 & 0.14 & 1590 & 255 & 100 & 0.80 & 253 & 170 & 13 & 5 \\
\hline $\mathrm{E} \_a-b$ & 6.4 & 6.1 & 1500 & 590 & 441 & 149 & 0.19 & 0.24 & 1350 & 487 & 280 & 0.68 & 164 & 131 & 36 & 21 \\
\hline E_hf & 3.5 & 4.6 & 2190 & 547 & 511 & 36 & 0.22 & 0.16 & 1640 & 395 & 16 & 0.71 & 110 & 69 & 16 & 10 \\
\hline UZM-12 & 7.0 & 6.4 & 1320 & 633 & 455 & 178 & 0.19 & 0.31 & 1095 & 450 & 270 & 0.75 & 175 & 150 & 41 & 25 \\
\hline
\end{tabular}


a)
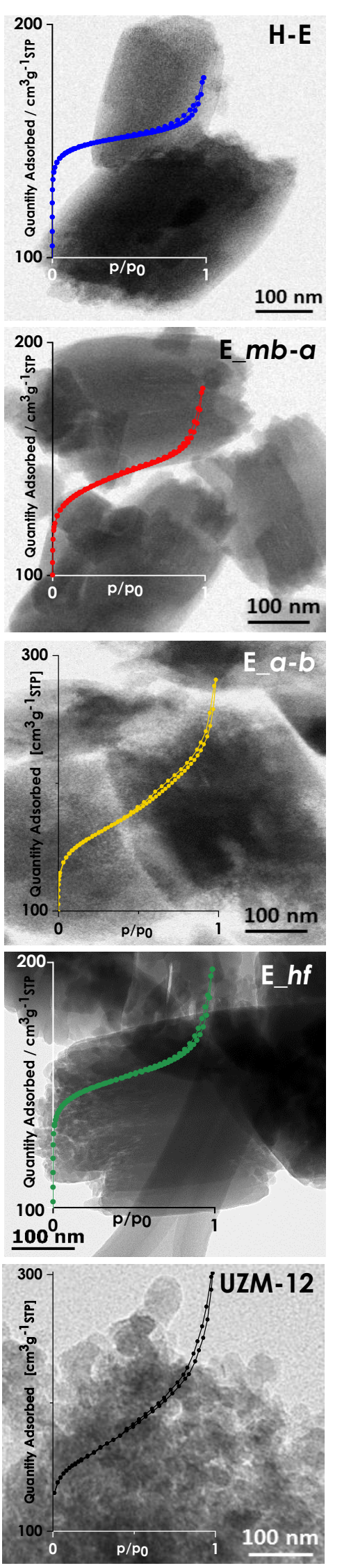
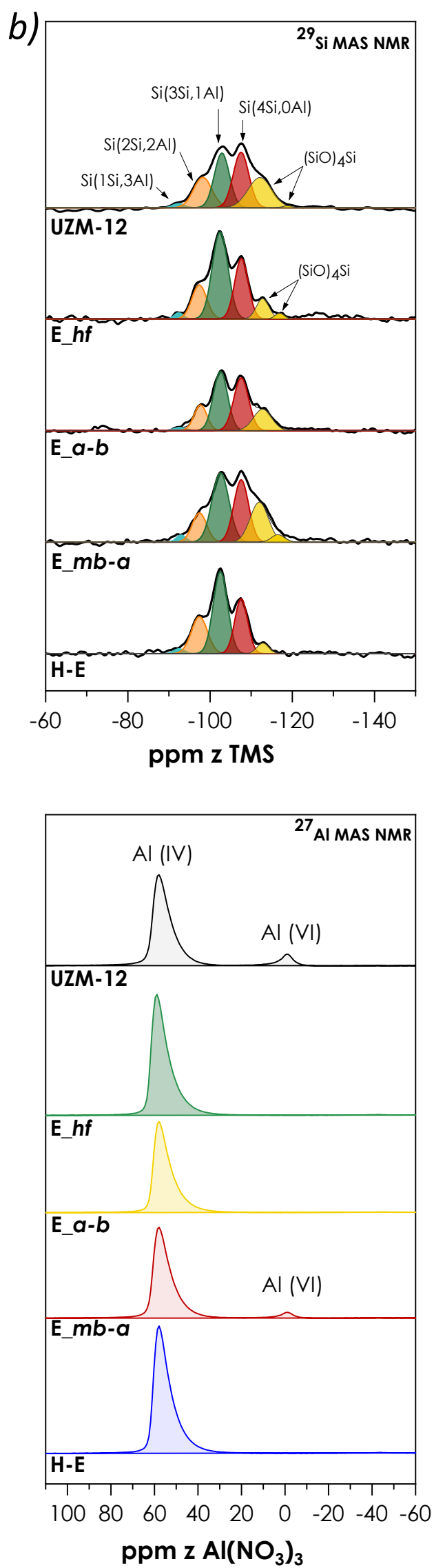

Fig. 2. (a) $N_{2}$ adsorption/desorption isotherms, STEM micrographs and (b) magic angle spinning NMR spectra of studied 
Many parameters can be tuned to obtain micro-mesoporous zeolites. The number of framework silicon atoms that could be removed without causing structural damage is governed by intrinsic features of the zeolites ( $\mathrm{Si} / \mathrm{Al}$ ratio and framework topology) and the conditions of its alkaline treatment (type and concentration of desilicating agent used). However, desilication not only creates mesopores, but also affects its acidity (nature, number, accessibility...).

The development of mesoporosity on the modified erionites increases their silanol content $\left(3747 \mathrm{~cm}^{-}\right.$ ${ }^{1}$ band, Fig.3a, $b$, Fig.3_SI). All demetallation procedures modify the population of the hydroxyls located both in 8- and 6-ring channels, however, the most significant changes arise from the acid dealumination followed by alkaline leaching ( $E_{-} a-b$ sample). This suggests that frameworks already distorted before dealumination are more prone to desilication. The increased mesoporosity leads to a higher Brønsted acid sites concentration determined by pyridine and ammonia adsorption monitored by IR spectroscopy (Table 1). Both on the E_a-b and UZ M-12 ca. $90 \%$ and $33 \%$ of the total aluminum content (calculated from the $\mathrm{Si} / \mathrm{Al}$ ) are titrated by ammonia and pyridine respectively. As expected, almost no acid sites are detected in purely microporous zeolite H-E and no substantial changes in their number and accessibility is found in $\mathrm{E}_{-} h f$ (fluoride treatment). However, upon the formation of a secondary mesopore system, the accessibility of Brønsted sites significantly increase, reaching $41 \%$ of the total amount of protonic sites for UZM-12 (Fig. 3c). The values of the accessibility factors for pyridine $\left(A F_{P_{y}}\right)$ and pivalonitrile $\left(A F_{P_{n}}\right)$ are a linear function of the mesopores surface area: the highest $A F_{P y}$ and $A F_{p n}$ values are observed for the sample with intercrystalline mesoporosity (UZM-12). These small crystallites develop a higher external surface possess more hydrogen bonded silanols (3730 $\mathrm{cm}^{-1}$ band). The top-down $\mathrm{E}_{-} a-b$ derivative, with intraparticle mesoporosity displays features (number and accessibility of acid sites) very similar to UZM-12. The higher basicity of pyridine and its lower kinetic diameter explains its higher $A F_{p y}$ than $A F_{p n}$, the one of the bulkier and less basic pivalonitrile molecule.

Ammonia thermodesorption $\left(\mathrm{NH}_{3(350)} / \mathrm{NH}_{3(170)}\right)$ indicates that all the above treatments reduce of the apparent acid strength of our derived materials. However, the confinement of a molecule adsorbed on an acid site can affect significantly its heat of adsorption and the latter decreases sharply with increasing pore diameter [37]. Therefore, the introduction of mesoporosity in zeolites shows the appearance of acid sites of "weaker" strength due to differences in confinement between acid sites located in the meso- and micro-porosity [23]. 

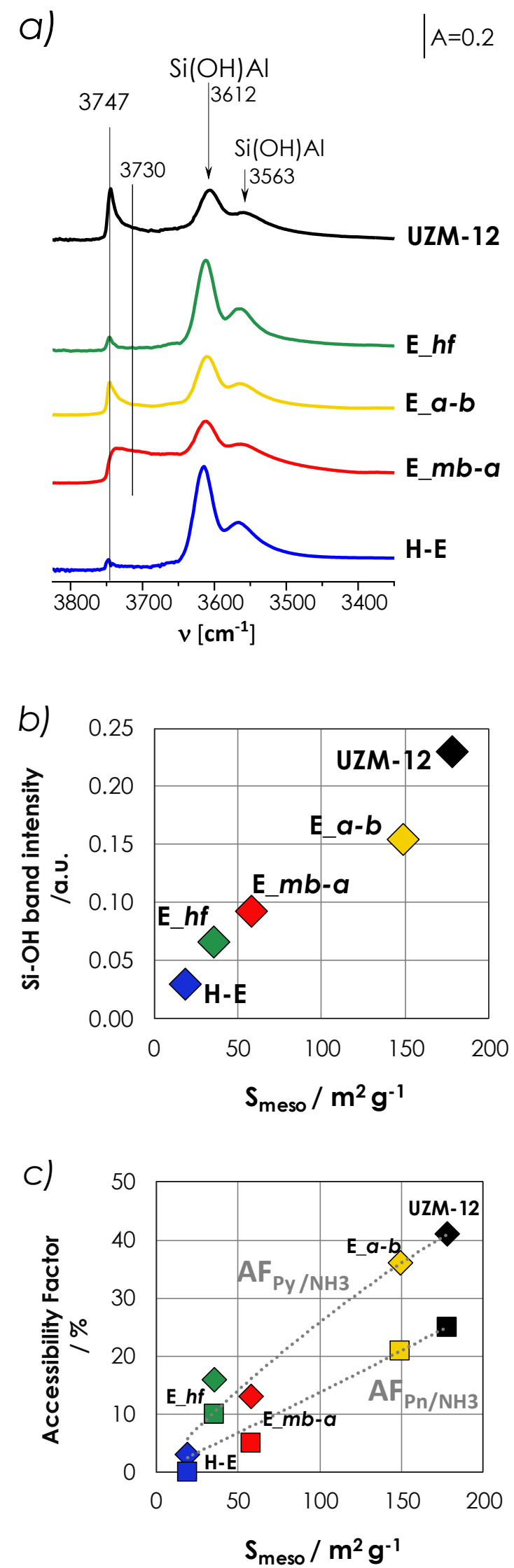

1 Fig. 3. (a) IR spectra of zeolites studied in the region of $\mathrm{O}-\mathrm{H}$ stretching vibrations and (b) area of the Si(OH) band region $2 \quad\left(3780-3680 \mathrm{~cm}^{-1}\right)$ and (c) accessibility of acid sites titrated by Py (diamonds) and pivalonitrile (squares) as a function of the 3 mesopores surface area. 
Acidity is not the only factor determining conversion and products selectivity in zeolite catalysis. Accessibility of the reagents to catalytically active sites often plays a crucial role in the diffusioncontrolled reactions. The kinetic diameter of TiPBz $(0.95 \mathrm{~nm})$ does not permit its entry in the ERI micropores $(0.51 \times 0.36 \mathrm{~nm})$ and it therefore probes only the catalytic activity of its external and mesoporous surface. During TiPBz dealkylation deactivation is always observed [36], so conversions at short time on stream need only to be considered as they best represent the state of the pristine catalyst surface (Fig. 4a). E_a-b, the ERI derivative with the highest external surface is indeed the most active ( $26 \%$ conversion vs. $6 \%$ for its parent) among the erionites with intracrystalline mesoporosity. A linear correlation between TiPBz conversion and mesopore surface area (Fig. $4 b$ ) indicates that the availability of more easily accessible protonic sites is responsible for this increased activity. UZM-12, a bottom-up ERI with almost similar external acidity $\left(P_{n}\right)$ and external surface area $\left(\mathrm{S}_{\text {meso }}\right)$ than the top-down $\mathrm{E}_{-} a-b$ zeolite displays very close catalytic performances. Both zeolites also display a plateau in their deactivation as a function of time, reminiscent of earlier observations in the methanol $[38,39]$ and ethanol $[40]$ to hydrocarbon conversions where nanosized zeolites, nanosheets or top-down hierarchical zeolites with high connectivity between their micro-and meso-porosity appear more tolerant to coke deposition as it is preferentially located on the zeolite external surface where it can act as an active site at pore mouths.

It is therefore important to note that acid site density on the external surface or external surface area are key descriptors to guide the design of zeolite catalysts by either bottom-up or top-down strategies.

Independently from the intra- or interparticle character of mesoporosity fabricated, cumene and DiPBzs are the main products of TiPBz cracking (Fig. 4c). A minor amount of benzene is also formed. Compared to 1,3-DiPBz, a lower yield of 1,4-DiPBz is obtained. The products distribution may suggest the dealkylation of TiPBz to 1,3-DiPBz in the first reaction step which is followed by isomerization of 1,3-DiPBz to 1,4-DiPBz on weakly acidic sites located on external surface. Indeed, the zeolite E_a-b with intracrystalline mesopore system provides the highest selectivity for 1,4-DiPBz while the 1,2-DiPBz is also detected for UZM-12. In further reaction steps the dealkylation of DiPBzs to cumene and dealkylation of cumene to benzene take place. Cumene cracking is however catalyzed by strong Brønsted acid sites, therefore only materials with native strength of sites (Table 1) offered the highest selectivity in this reaction. The benzene fraction nearly absent for all of the catalysts can be ascribed to the lack of the strong Brønsted acid sites on the newly generated mesopore surface and inevitably their poor accessibility in 8-ring channels to cumene molecule. 

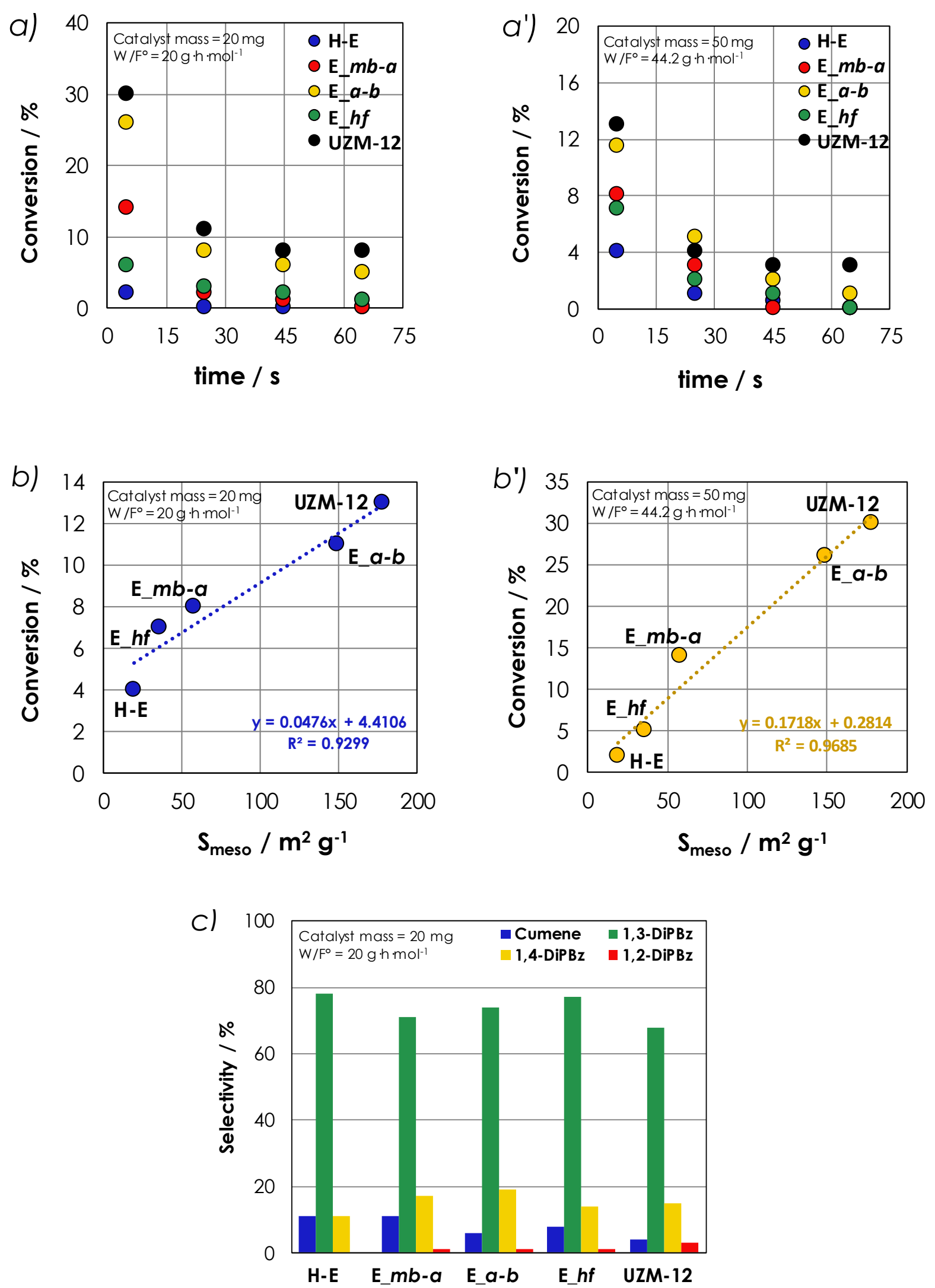

Fig. 4. (a) Conversion evolution in time in TiPBz dealkylation (b) conversions at short time on stream and a function of the mesopores surface area and (c) selectivity of the erionites studied in 1,3,5-triisopropylbenzene dealkylation at $20 \mathrm{~g} \cdot \mathrm{h} \cdot \mathrm{mol}{ }^{-1}$. 
2 Consecutive acid $\left(\mathrm{HNO}_{3}\right)$ and caustic $(\mathrm{NaOH})$ leaching to control silicon and aluminum atoms 3 extraction from an erionite framework, is a most effective approach to create intracrystalline 4 porosity in hierarchical zeolites with 8-membered rings. It is remarkable that adding mesoporosity in erionite by such a top-down approach $\left(c a .150 \mathrm{~m}^{2} \cdot \mathrm{g}^{-1}\right.$ ) is as efficient as designing, by a bottom-up approach, the structurally equivalent nanosized zeolite UZM-12 $\left(c a .178 \mathrm{~m}^{2} \cdot \mathrm{g}^{-1}\right)$. The demetallation procedure not only creates mesopores in the zeolite, but also increases the accessibility of their acid sites. The enhanced accessibility of protonic sites in hierarchical erionite $E_{-} a-b$ and the nanosized UZM-12 has a significant impact on the initial conversion of TiPBz dealkylation.

Fine-tuning of the acidic and some catalytic properties of the ERI structure can therefore be achieved either by well-planned top-down of bottom-up procedures.

\section{ACKNOWLEGMENTS}

This work was financed by Grant No. 2015/18/E/ST4/00191 from the National Science Centre, Poland. The STEM studies were realized within the frame of the project "Infrastructure Improving of Centre of Excellence of Advanced Materials with Nano- and Submicron- Structure", which is supported by the operational Program "Research and Development" financed through European Regional Development Fund.

\section{AUTHOR CONTRIBUTIONS}

20 The manuscript was written through contributions of all authors. All authors have given approval to 21 the final version of the manuscript.

23 The authors declare no conflict of interest. 
2 [1] A.S. Eakle, Am. J. Sci. 6 (1898) 66.

3 [2] M.A. Hernandez, L. Corona, F. Rojas, Adsorption 6 (2000) 33-45.

4

REFERENCES

[3] L.W. Staples, J.A. Gard, Mineral. Mag. 32 (1959) 261-281.

[4] A. Alberti, A. Martucci, E. Galli, G. Vezzalini, Zeolites 19 (1997) 349-352.

[5] N.J. Chen, J. Maziuk, A.B. Schwartz, P. Weisz, Oil Gas J. 66 (1968) 154-157.

[6] N.Y. Chen, W.E. Garwood, Ind. Eng. Chem. Process Des. Dev. 17 (1978) 513-518.

[7] N.J. Chen, W.E. Garwood, J. Catal. 53 (1978) 284. Hydrocarb. Process., ACS Symposium Series, 738, 1999, pp. 18-38. [accessed on, 2018-02-19], Natl. Cancer Inst. (2015). (2010) 12971-12982. Stud. Surf. Sci. Catal. 170 (2007) 487-492.

[12] Y. Tao, H. Kanoh, L. Abrams, K. Kaneko, Chem. Rev. 106 (2006) 896-910. 946-960. 504-513. Mater. 188 (2014) 99-107. Tsapatsis, T. Okubo, Chem. Mater. 28 (2016) 8997-9007. 313.

[18] K. Zhang, M.L. Ostraat, Catal. Today 264 (2016) 3-15. 13062-13065.

[8] P.B. Weisz, in: C. Song, J.M. Garces, Y. Sugi (Eds.), Shape-Selective Catal. Chem. Synth.

[9] Https://www.cancer.gov/about-cancer/causes-prevention/risk/substances/erionite.

[10] J.H. Lee, M.B. Park, J.K. Lee, H.K. Min, M.K. Song, S.B. Hong, J. Am. Chem. Soc. 132

[11] M.A. Miller, G.J. Lewis, J.G. Moscoso, S. Koster, F. Modica, M.G. Gatter, L.T. Nemeth,

[13] K. Egeblad, C.H. Christensen, M. Kustova, C.H. Christensen, Chem. Mater. 20 (2008)

[14] J. Aguado, D.P. Serrano, J.M. Rodríguez, Microporous Mesoporous Mater. 115 (2008)

[15] P. Losch, M. Boltz, K. Soukup, I.H. Song, H.S. Yun, B. Louis, Microporous Mesoporous

[16] S.H. Keoh, W. Chaikittisilp, K. Muraoka, R.R. Mukti, A. Shimojima, P. Kumar, M.

[17] Q. Zhu, M. Liang, W. Yan, W. Ma, Microporous Mesoporous Mater. 278 (2019) 307-

[19] J.C. Groen, J.C. Jansen, J.A. Moulijn, J. Pérez-Ramírez, J. Phys. Chem. B 108 (2004)

[20] M. Silaghi, C. Chizallet, P. Raybaud, Microporous Mesoporous Mater. 191 (2014) 82- 
96.

[21] J.C. Groen, L.A.A. Peffer, J.A. Moulijn, J. Pérez-Ramírez, Chem. - A Eur. J. 11 (2005) 4983-4994.

[22] K.A. Tarach, J. Tekla, W. Makowski, U. Filek, K. Mlekodaj, V. Girman, M. Choi, K. GóraMarek, Catal. Sci. Technol. 6 (2016) 3568-3584.

[23] K. Tarach, K. Góra-Marek, J. Tekla, K. Brylewska, J. Datka, K. Mlekodaj, W. Makowski, M.C. Igualada López, J. Martínez Triguero, F. Rey, J. Catal. 312 (2014) 46-57.

[24] J. Pérez-Ramírez, S. Abelló, A. Bonilla, J.C. Groen, Adv. Funct. Mater. 19 (2009) 164172.

[25] K. Góra-Marek, K. Tarach, J. Tekla, Z. Olejniczak, P. Kus̈trowski, L. Liu, J. MartinezTriguero, F. Rey, J. Phys. Chem. C 118 (2014) 28043-28054.

[26] W.E. Garwood, N.Y. Chen, J.C. Bailar, Inorg. Chem. 15 (1976) 1044-1047.

[27] D. Verboekend, T.C. Keller, M. Milina, R. Hauert, J. Pérez-Ramírez, Chem. Mater. 25 (2013) 1947-1959.

[28] Z. Qin, J.P. Gilson, V. Valtchev, Curr. Opin. Chem. Eng. 8 (2015) 1-6.

[29] K.A. Tarach, J. Tekla, U. Filek, A. Szymocha, I. Tarach, K. Góra-Marek, Microporous Mesoporous Mater. 241 (2017) 132-144.

[30] H. Baser, T. Selvam, J. Ofili, R. Herrmann, W. Schwieger, in: R. Xu, Z. Gao, J. Chen, W.B.T.-S. in S.S. and C. Yan (Eds.), From Zeolites to Porous MOF Mater. - 40th Anniv. Int. Zeolite Conf., Elsevier, 2007, pp. 480-486.

[31] J. Rouquerol, P. Llewellyn, F. Rouquerol, in: F.R.-R. P.L. Llewellyn J. Rouqerol and N. Seaton BT - Studies in Surface Science and Catalysis (Ed.), Charact. Porous Solids VII Proc. 7th Int. Symp. Charact. Porous Solids (COPS-VII), Aix-En-Provence, Fr. 26-28 May 2005, Elsevier, 2007, pp. 49-56.

[32] J. Datka, K. Góra-Marek, Catal. Today 114 (2006) 205-210.

[33] K. Góra-Marek, M. Derewiński, P. Sarv, J. Datka, Catal. Today 101 (2005) 131-138.

[34] K. Sadowska, K. Góra-Marek, J. Datka, Vib. Spectrosc. 63 (2012) 418-425.

[35] K. Sadowska, K. Góra-Marek, J. Datka, J. Phys. Chem. C 117 (2013) 9237-9244.

[36] M. Mattioli, M. Giordani, M. Dogan, M. Cangiotti, G. Avella, R. Giorgi, A.U. Dogan, M.F. Ottaviani, J. Hazard. Mater. 306 (2016) 140-148.

[37] R.J. Gorte, Catal. Letters 62 (1999) 1-13.

[38] M. Choi, K. Na, J. Kim, Y. Sakamoto, O. Terasaki, R. Ryoo, Nature 461 (2009) 246-249. 
1 [39] J. Kim, M. Choi, R. Ryoo, J. Catal. 269 (2010) 219-228.

2 [40] L. Lakiss, F. Ngoye, C. Canaff, S. Laforge, Y. Pouilloux, Z. Qin, M. Tarighi, K. Thomas, V. 3 Valtchev, A. Vicente, L. Pinard, J.P. Gilson, C. Fernandez, J. Catal. 328 (2015) 165-172. 